\title{
Histopathological Spectrum of Upper Gastrointestinal Endoscopic Biopsies in a Tertiary care centre
}

\author{
Anjana M.L* and Kavitha Yevoor \\ Department of Pathology, Karnataka Institute of Medical Sciences, Hubli
}

\begin{abstract}
Background: Upper GI endoscopy is an established procedure for investigating a wide range of upper GI conditions especially inflammatory and malignant diseases of stomach and esophagus. A good correlation in diagnosis can be achieved by complementing endoscopic findings with histopathology of biopsy specimens.

Methods: Both retrospective and prospective study of upper GI endoscopic biopsy was carried out at department of pathology, KIMS, Hubli during January 2016 to December 2018. Samples were received in 10\% formalin; routine processing was followed with H \& E staining. Special stain like Giemsa was done for detection of H. Pylori. 396 endoscopic mucosal biopsies were analyzed and evaluated.

Result: Out of 396 cases, 250 cases were esophageal biopsies, 104 cases were gastric biopsies \& 42 cases were duodenal biopsies. The male: female ratio was 1:9:1. The highest number of cases was seen between 61 to 70 years. Dyspepsia was the common symptom seen in $61.3 \%$. The most common lesions encountered in the esophagus were carcinomas $(67 \%)$ followed by esophagitis (16\%). The commonly encountered gastric lesion was chronic gastritis in 54.8\% with H. pylori gastritis being positive in $38.18 \%$. Among the duodenal biopsies, non-neoplastic lesions were most common (59.5\%) followed by neoplastic lesions $(26 \%)$.
\end{abstract}

Conclusion: Upper GI endoscopy is an effective and appropriate preliminary investigation to assess patients with dysphagia, dyspepsia, vomiting. Endoscopy without biopsy is incomplete and that the combination of methods offers a strong diagnostic tool for better patient care.

Keywords: Upper Gastrointestinal Endoscopic Biopsy, Histopathology, Neoplastic Lesions.

\section{Introduction}

Endoscopy is a simple procedure that is safe and tolerated well. The use of versatile endoscopy has resulted in a marked increase in diagnostic procedures involving the upper and lower GI tract visualization and biopsy. The signs of endoscopic biopsy of the upper GI tract include: diagnosis of dyspepsia, odynophagia, gastroesophageal reflux disorders, Barrett's esophagus, dysplasia, peptic ulcer disease, esophageal and gastric carcinomas. ${ }^{[1]}$

Different pathologies involving the upper GI tract manifest with a similar group of symptoms that may be difficul to determine medically. There are several diagnostic studies in the evaluation of these symptoms where endoscopy is the initial diagnostic test performed. ${ }^{[2]}$ Histology is often regarded in routine clinical practice as the 'Gold standard' against which other studies are carried out. ${ }^{[3]}$

Worldwide, carcinoma stomach is the second most common cancer, and carcinoma oesophagus is the sixth leading cause of death. ${ }^{[4,5]}$ According to the national cancer registry, oesophageal and gastric cancer are most frequently found in men, while oesophageal cancer ranks third in women following carcinoma cervix. ${ }^{[6]}$ Early malignancy detections greatly enhance patient rate survival. The 5-year survival rate of early esophageal cancer is 83.5 percent and 90 percent or more for early gastric cancer. ${ }^{[7]}$

\section{Materials and Methods}

Descriptive study of 3 years from January 2016 to December 2018 was done. The study was done on upper gastrointestinal tract endoscopic biopsies received for routine histopathological evaluation in the department of pathology, Karnataka institute of medical sciences, Hubli.

Inclusion Criteria: All endoscopic mucosal biopsies of esophageal, gastric and duodenal (1st part and $2^{\text {nd }}$ part) lesions. Exclusion Criteria: 1. Inadequate biopsies. 2. Patients presenting with lesions in the oral cavity and pharynx. 3. Patients presenting with lesions beyond the second part of duodenum (D2).

The patient details like age, sex, presenting complaints, clinical findings and endoscopic findings were obtained from the requisition form that was sent along with biopsy samples. Written informed consent was taken from the patients regarding the study undertaken and information disclosed. 
Upper gastrointestinal endoscopic biopsy samples received in $10 \%$ formalin were taken for the study. While embedding care was taken to see that the mucosal surface was placed 90 degrees to the cutting surface. Five micrometre thick sections were cut on a Leica microtome. Hematoxylin and Eosin staining was done on all biopsies. Special stain like Giemsa was done for the detection of H. pylori.

\section{Result}

Out of 396 upper GI endoscopic biopsy samples that were studied during the period of 3 years, $250(63.13 \%)$ were from the esophagus, $104(26.26 \%)$ from stomach and 42 (10.6\%) from duodenum as depicted in Fig.1.

The highest number of biopsies was done in patients between 61 to 70 years $(29.29 \%)$ followed by 51-60 years (24.74\%) and 41-50 years (20.2\%). Out of 396 patients, 261(65.9\%) were males and 135(34.1\%) were females. The male: female ratio being 1.9:1.

Dyspepsia was the commonest presentation in 59\% of patients. Dysphagia was the next commonest presentation in $44 \%$ of patients. Pain abdomen was seen in $25 \%$ of patients. Loss of weight was common to all carcinomas.

The total number of esophageal biopsies were 250. The commonly encountered esophageal lesion in upper GI biopsies was squamous cell carcinoma (62\%) followed by chronic esophagitis (16\%) and dysplasia (5\%) as shown in Table 1. Majority of the cases of carcinoma esophagus were in the middle $1 / 3^{\text {rd }}$ which included squamous cell carcinoma and adenosquamous carcinoma. However, all cases of adenocarcinoma were in the lower $1 / 3^{\text {rd }}$ of the esophagus.

Commonly encountered gastric lesions were non neoplastic lesions among which chronic gastritis comprised of $54.8 \%$ of the cases, malignancy was seen in $28.8 \%$ cases and benign neoplasm in $6.7 \%$ cases as shown in Table 2 . Among malignancies, one case was diagnosed as secondary gastric non-Hodgkin's lymphoma. (Fig. 3B). This comprises of only $0.9 \%$ of gastric lesions as metastases in the stomach are rare and marks advanced disease.

Most common site of involvement in gastric lesions was the gastric antrum followed by body of the stomach. Total number of chronic gastritis cases were 55, among which 21 $(38.18 \%)$ cases were positive for $\mathrm{H}$. pylori and 34 (61.8\%) cases were negative for $\mathrm{H}$. pylori.

The commonly encountered duodenal lesion in upper GI biopsies was chronic duodenitis which constituted $25(59.5 \%)$ cases. Malignancy was seen in $6(14.2 \%)$ cases and benign neoplasm in $5(11.9 \%)$ cases as shown in Table 3.

Out of 396 upper GI biopsies, 168(67\%) cases were esophageal malignancies, $30(28.8 \%)$ cases were gastric malignancies and $6(1.4 \%)$ cases were duodenal malignancies. The overall incidence of malignancy in the study was 204(51.5\%) cases as shown in Table 4.

Table 1: Distribution of oesophageal lesions based on histopathological diagnosis.

\begin{tabular}{|l|l|l|}
\hline Histopathological diagnosis & No. of cases & Percentage \\
\hline Squamous cell carcinoma & 154 & $61.6 \%$ \\
\hline Adenocarcinoma & 11 & $4.4 \%$ \\
\hline Adenosquamous carcinoma & 3 & $1.2 \%$ \\
\hline Benign & 13 & $5.2 \%$ \\
\hline Chronic esophagitis & 40 & $16 \%$ \\
\hline Dysplasia & 13 & $5.2 \%$ \\
\hline Barrett's esophagus & 6 & $2.4 \%$ \\
\hline Fungal esophagitis & 2 & $0.8 \%$ \\
\hline No significant pathology & 8 & $3.2 \%$ \\
\hline Total & $\mathbf{2 5 0}$ & $\mathbf{1 0 0} \%$ \\
\hline
\end{tabular}

Table 2: Distribution of gastric lesion based on histopathological diagnosis.

\begin{tabular}{|l|l|l|}
\hline Histopathological diagnosis & No. of cases & Percentage \\
\hline Chronic gastritis & 55 & $52.8 \%$ \\
\hline Acute gastritis & 3 & $2.8 \%$ \\
\hline Polyps & 7 & $6.7 \%$ \\
\hline Adenocarcinoma & 23 & $22.1 \%$ \\
\hline
\end{tabular}




\begin{tabular}{|l|l|l|}
\hline Histopathological diagnosis & No. of cases & Percentage \\
\hline Signet ring cell carcinoma & 5 & $4.8 \%$ \\
\hline Dysplasia & 4 & $3.8 \%$ \\
\hline Peptic ulcer disease & 2 & $1.9 \%$ \\
\hline No significant pathology & 3 & $2.8 \%$ \\
\hline Secondary Lymphoma & 1 & $0.9 \%$ \\
\hline Carcinoid & 1 & $0.9 \%$ \\
\hline TOTAL & 104 & $100 \%$ \\
\hline
\end{tabular}

Table 3: Distribution of duodenal lesions based on histopathological diagnosis.

\begin{tabular}{|l|l|l|}
\hline Histopathological diagnosis & No. of cases & Percentage \\
\hline Chronic duodenitis & 25 & $59.5 \%$ \\
\hline Erosive duodenitis & 1 & $2.3 \%$ \\
\hline Polyps & 5 & $11.9 \%$ \\
\hline Candidiasis & 1 & $2.3 \%$ \\
\hline Malabsorption syndrome & 2 & $4.7 \%$ \\
\hline Adenocarcinoma & 6 & $14.2 \%$ \\
\hline No significant pathology & 2 & $4.7 \%$ \\
\hline TOTAL & $\mathbf{4 2}$ & $100 \%$ \\
\hline
\end{tabular}

Table 4:Incidence of malignancy in upper GI Biopsies.

\begin{tabular}{|l|l|l|}
\hline Site & No. of cases & Percentage \\
\hline Esophageal malignancies & 168 & $67 \%$ \\
\hline Gastric malignancies & 30 & $28.8 \%$ \\
\hline Duodenal malignancies & 6 & $1.4 \%$ \\
\hline TOTAL & $\mathbf{2 0 4}$ & $\mathbf{1 0 0 \%}$ \\
\hline
\end{tabular}

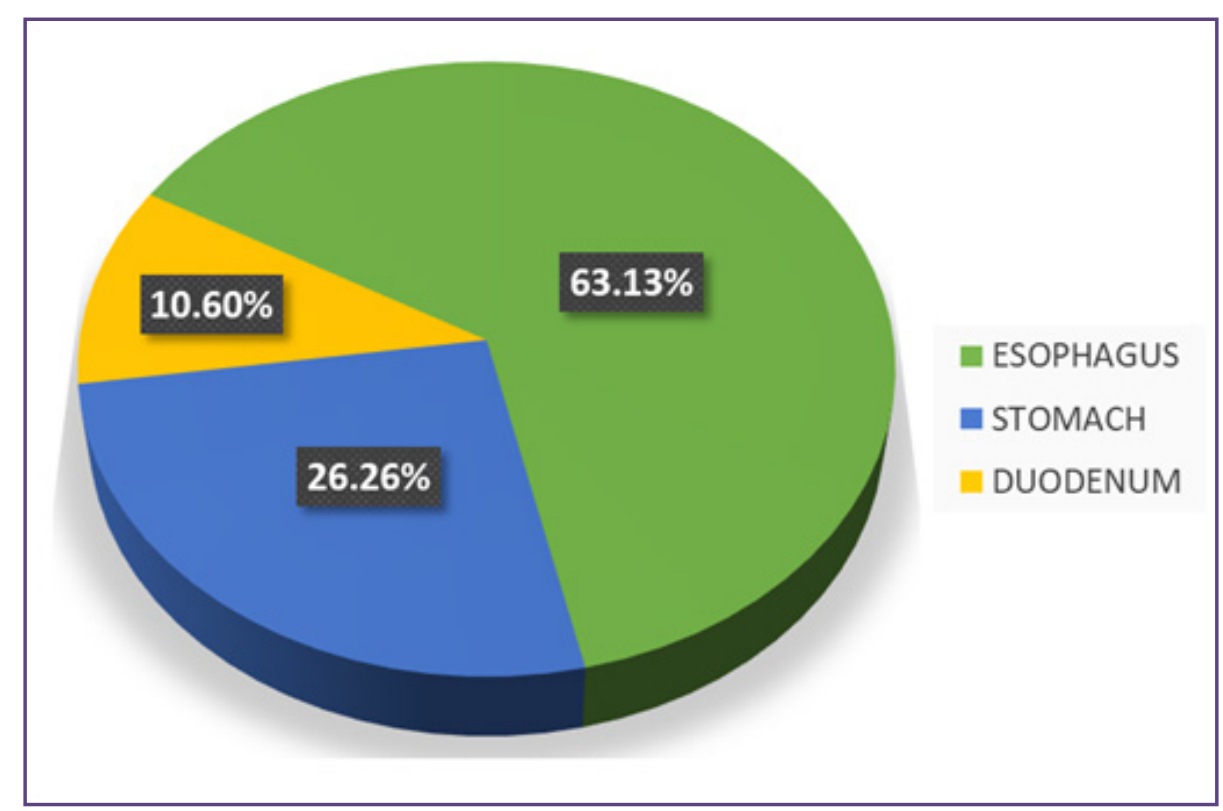

Fig. 1: Site wise distribution of upper GI endoscopic biopsies. 


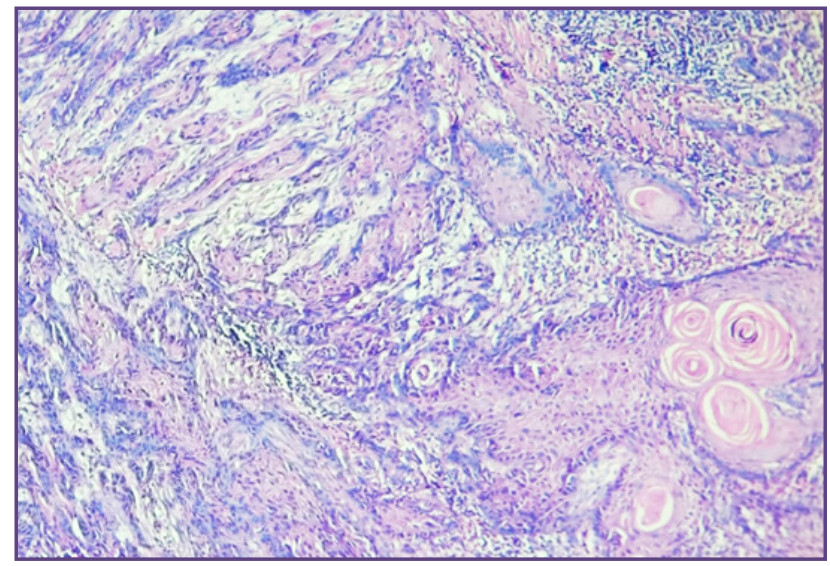

Fig. 2: Photomicrograph showing well differentiated squamous cell carcinoma of oesophagus (H\&E, 10X).

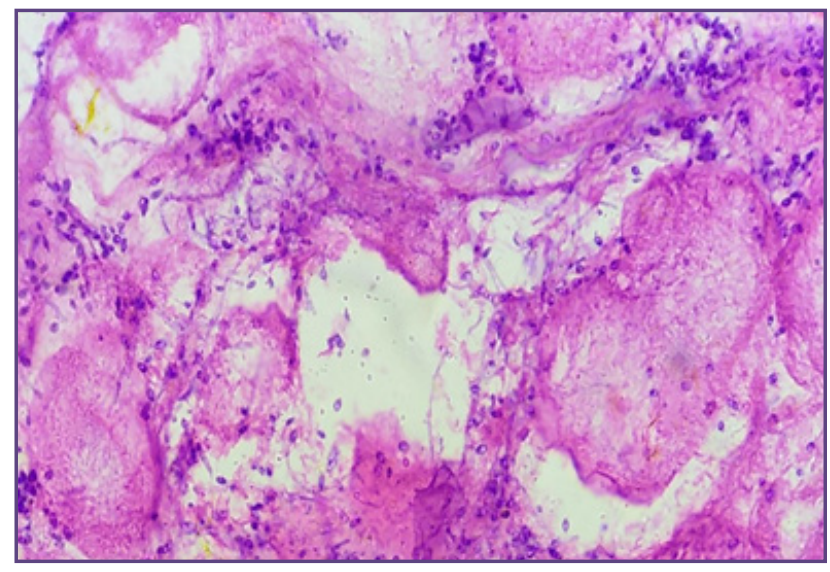

Fig. 4: Photomicrograph showing candidiasis of duodenum (H\&E, 40X).

\section{Discussion}

The present study shows highest number of upper GI endoscopic biopsies between 61-70 years of age similar to studies by Jaynul Islam et al ${ }^{[8]}$ and P Uma rani et al. ${ }^{[9]}$ The male: female ratio in the present study is $1.9: 1$. This is also similar to studies done by P Uma rani et al ${ }^{[9]}$ and Krishnappa Rashmi et al ${ }^{[10]}$ in which the ratio is $3: 1$ and 2:1 respectively.

Among the upper GI endoscopic biopsies, the commonest site of biopsies in literature has been the stomach as observed in studies by Abhilash et al ${ }^{[11]}$ and Krishnappa Rashmi et al. ${ }^{[10]} \mathrm{A}$ contrasting pattern was seen in present study where esophageal biopsies comprised majority of cases $(63 \%)$. Most of them turned out to be squamous cell carcinoma showing male predominance. This may be due to exposure to risk factors in rural population as our institute gets majority of patient load from rural areas of north Karnataka where tobacco chewing is more common than urban areas. ${ }^{[12]}$ This is comparable to study done by

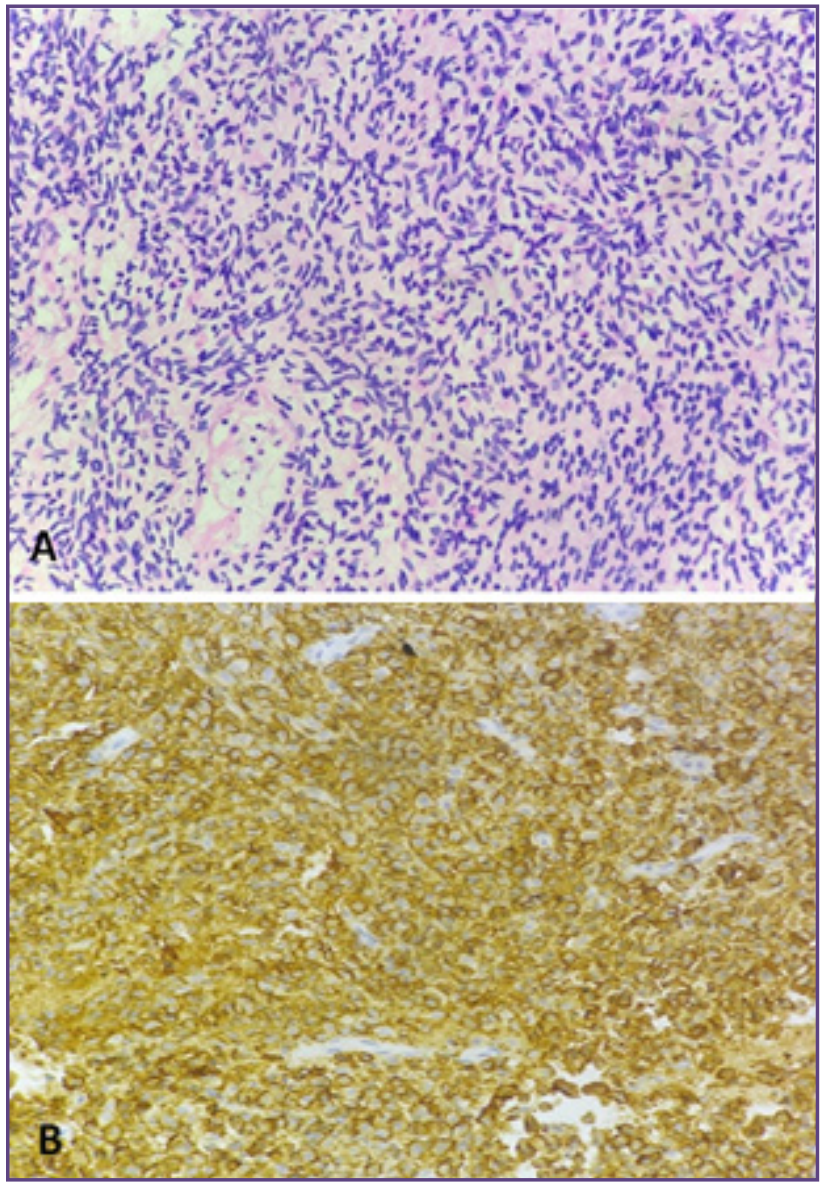

Fig. 3: A: Photomicrograph showing GIST of stomach (H\&E, 40X), B: Photomicrograph showing CD 20 positivity in secondary gastric NHL (IHC, 40X).

Sandhya et al ${ }^{[13]}$ in which the author states $>80 \%$ of cases of oesophageal carcinoma can be attributed to the exposure of tobacco, alcohol and chewing betel leaf.

In our study dyspepsia was the commonest clinical presentation followed by dysphagia and pain abdomen. This is comparable with the study done by Gillen et al ${ }^{[14]}$ in which author states that high prevalence and incidence of dyspepsia in the population is the most common reason for requesting an upper endoscopy. Now shad et $\mathrm{al}^{[15]}$ also states that in dyspeptic patients' proper history, physical examination and therapeutic trial followed by selected investigations are required to confirm or exclude serious diseases.

The commonly encountered lesion in esophagus was malignancy which is similar to the study done by Abhilash et al. ${ }^{[1]}$ Among squamous cell carcinoma of esophagus, most common was moderately differentiated carcinoma $(83.1 \%)$ followed by well differentiated $(11.6 \%)$ and poorly differentiated carcinoma (5.1\%). This 
correlates with the studies done by Vidyavathi et $\mathrm{al}^{[16]}$ and Krishnapparashmi et al. ${ }^{[10]}$

The commonly encountered gastric lesions were non neoplastic lesions (gastritis 14.3\%) like in other studies. ${ }^{[13]}$ In present study $\mathrm{H}$. pylori was positive in $38 \%$ of chronic gastritis cases which is more than that noticed in studies done by Qureshi et $\mathrm{al}^{\left[{ }^{17]}\right.}$ and Choomsri et $\mathrm{al}^{[18]}$ and less than that seen in few other studies like Jemilohun et al. ${ }^{[19]}$ This variation seen in incidence of $\mathrm{H}$. pylori depends on several factors. One of them being proper orientation of foveolae in biopsy(as organism are seen in gastric foveolae, thin sections with proper staining \& special stains used in the detection of these micro-organisms). ${ }^{[20]}$ The incidence also varies among studies depending on socio-economic conditions, poverty, overcrowding, poor sanitation and poor hygiene. ${ }^{[21]}$

In the present study $28(7 \%)$ cases were diagnosed as gastric adenocarcinoma which correlates with the study done by Sandhya et al. ${ }^{[13]}$

With respect to differentiation of gastric adenocarcinoma, moderately differentiated adenocarcinoma was more common than the well differentiated carcinoma, which was also in concordance with other studies. ${ }^{[22]}$ Alcohol consumption, dietary factors, smoking and social habits have been proposed as risk factors for gastric cancer. ${ }^{[23]}$

Duodenitis $(6.3 \%)$ is the most common duodenal lesion encountered in our study similar to the study done by Sandhya et al. ${ }^{[13]}$

\section{Conclusion}

Biopsy provides an excellent opportunity for the clinician and histopathologist to correlate the clinical data, endoscopic findings with pathological lesions. In routine clinical practice, histology is considered as the "gold standard" for definitive diagnosis of various lesions. Malignancies both carcinomas and lymphomas can be easily diagnosed. Endoscopic biopsies can also detect changing patterns in the spectrum of lesions besides detecting upper GI mucosal lesions at an early stage especially atrophy, intestinal metaplasia and dysplasia so as to prevent progression of these lesions to invasive cancer.

\section{Abbreviations}

- GI: Gastrointestinal

- GIST: Gastrointestinal stromal tumour

- H\&E: Haematoxylin and Eosin

- H. pylori: Helicobacter pylori

- IHC: Immunohistochemistry

- NHL: Non-Hodgkin's lymphoma

\section{Acknowledgements}

I am grateful to Head of department, Pathology for giving permission to conduct the study

\section{Funding}

There is no source of funding

\section{Competing Interests}

There are no conflict of interest

\section{Reference}

1. Gulia SP, Chaudary M, Noorunisa N, Balakrishna CD, Balagurunathan K. Interpretation of Upper Gastrointestinal Tract Endoscopic Mucosal Biopsies - A Study Conducted In Teaching Hospital In Puducherry, India. Int J Med Health Sci. 2012 July;1(3):17-24.

2. Varadarajulu S, Eloubeidi MA, Patel RS, Mulcahy HE, Barkun A et al: The yield and the predictors of esophageal pathology when upper endoscopy is used for the initial evaluation of dysphagia. Gastrointest Endosc. 2005 Jun 1;61(7):804-8.

3. AfzalS, AhmadM, MubarikA, SaaedF, RafiS, SaleemN, Hussain A. Morphological spectrum of gastric lesionsEndoscopic biopsy findings. Pak Armed force Med J. 2006 june;56(2):143-9.

4. Zhang XF, Huang CM, Lu HS, Wu XY, Wang C, Guang GX, et al. Surgical treatment and prognosis of gastric cancer in 2613 patients. World J Gastroenterol 2004 Dec 1;10(23):3405-08.

5. Enzinger PC, Mayer RJ. Oesophageal Cancer. N Engl J Med 2003 Dec 4;349(23):2241-52.

6. Comparison of cancer incidence and patterns, Chapter 6, Comparison of Age Adjusted Incidence Rates. Consolidated Report of the PBCRs 2001-2004:54-68.

7. Kato H, Tachimori Y, Watanube H, Yamaguchi H, Ishikawa J, Itabashi M. Superficial oesophageal carcinoma: surgical treatment and results. Cancer 1990 Dec 1;66(11):2319-23.

8. Islam SM, Ahmed AM, Ahmad MS, Hafiz SA. Endoscopic and histologic diagnosis of upper gastrointestinal lesions, Experience in a port city of Bangladesh. Chattagram MaaO-Shishu Hospital Medical College Journal. 2014 Nov 28;13(3):11-4.

9. P Uma Rani, N Ramya, C Swathi. Efficacy of endoscopic biopsies in establishing histologic diagnosis of upper gastrointestinal tract lesions - A one year prospective study. IP Journal of Diagnostic Pathology and Oncology. 2017 OctDec;2(4):91-94.

10. Krishnappa R, Horakerappa MS, Ali K, Gouri M. A study on histopathological spectrum of upper gastrointestinal tract endoscopic biopsies. Int J Med Res Health Sci. 2013;2(3):418-24.

11. Abilash SC, Hasaf K, Gitanjali MM, Shreelaxmidevi S, Balamuruganvelu S. Histopathologic spectrum of upper 
gastrointestinal tract mucosal biopsies: A retrospective study. Sch. J. App. Med. Sci. 2016;4(5):1807-13.

12. Singh A, Ladusingh L. Prevalence and determinants of tobacco use in India: evidence from recent Global Adult Tobacco Survey data. PloS one. 2014 Dec 4;9(12):e114073.

13. Sandhya PG, Madhusudan C, Naseem N, Balkrishnan CD, Balagurunathan K. Interpretation of upper gastrointestinal tract endoscopic mucosal biopsies- A study conducted in teaching hospital in Punducherry, India. International Journal of Medical and Health Sciences 2012;1(3):17-24.

14. Gillen D, MeColl KE. Does concern about missing malignancy justify endoscopy in uncomplicated dyspepsia in patients less than 55? Am J Gastroenterol 1999;94:75-79.

15. Khan N, Shabbir G, Zarif M, Khattak MI. Upper Gastrointestinal Endoscopic Assessment of Patients Presenting With Dyspepsia. JPMI 2007;21(3):212-16.

16. Vidyavathi K, Harendrakumar ML, Kumar YL. Correlation of endoscopic brush cytology with biopsy in diagnosis of upper gastrointestinal neoplasms. Indian Journal of Pathology and Microbiology. 2008 Oct 1;51(4):489-92.

17. Qureshi NA, Hallissey MT, Fielding JW. Outcome of index upper gastrointestinal endoscopy in patients presenting with dysphagia in a tertiary care hospital- A 10 years review. BMC Gastroenterology. 2007;7(1):43.

18. Choomsri P, Bumpenboon W, Wasuthit Y, Euanorasetr C, Sumitpradit P, Suwanthunma W. Upper gastrointestinal endoscopy findings in patients presenting with dyspepsia. The Thai journal of Surgery 2010;31:7-12.

19. Jemilohun AC, Otegbayo JA, Ola SO, Oluwasola OA, Akere A. Prevalance of Helicobacter pylori among Nigerian patients with dyspepsia in Ibadan. Pan African Medical Journal. 2010;6(1).

20. Farinha P, Gascoyne RD. Helicobacter pylori and MALT lymphoma. Gastroenterol 2005;128:1579-1605.

21. Gonzaga L, Coelho V, Barua RL, Emm Q. Latin-American consensus conference on helicobacter pylori infection. Amer J Gastroenterol 2000;95:2688-91.

22. Rumana M, Khan AR, Khurshid N. The changing pattern of oesophago-gastric cancer in Kashmir. JK Pract. 2005;12(4):189-92.

23. Gajalakshmi V, Swaminathan R, Shanta V. An independent survey to assess completeness of Registration: Population based cancer registry, Chennai, India. Asian Pac J Cancer Prev. 2001;2(3):179-83.

*Corresponding author:

Dr. Anjana M.L, Maruthi nivasa,1st main, 2nd cross, Opposite Mandara Park, Gokula extension, Tumkur, Karnataka-572104

Phone: +91 8951109225

Email: gowda.anjana90.ag@gmail.com

Date of Submission : 02/05/2021

Date of Final Revision : 31/05/2021

Financial or other Competing Interests: None.

Date of Acceptance : 05/06/2021

Date of Publication : 31/06/2021 